\title{
Social aspects of mine closure: the elephant in the room
}

\author{
J Edwards SRK Consulting (South Africa) (Pty) Ltd, South Africa \\ A Maritz SRK Consulting (South Africa) (Pty) Ltd, South Africa
}

\begin{abstract}
Social aspects of mine closure are often not well understood, resulting in some companies either avoiding or postponing the development and implementation of sustainable social closure strategies. Delaying planning for social closure may cost companies money and incur reputational damage instead of leaving a lasting positive legacy encompassing sustainable post-mining opportunities for mining-affected communities.

Within the South African context, the concept of social licence to operate is gaining traction and many companies are actively adopting policies and management practices to address this key requirement. Similarly, the value of involving communities in project planning and design to obtain a shared view on how the project will operate and close, and therefore impact on its stakeholders is gaining momentum. The benefits of co-production, a practical approach that can also assist in mitigating the negative social and environmental impacts of mine closure, has shown many benefits. These benefits include pride and a sense of ownership as well as the opportunity to develop tailored solutions that speaks specifically to each affected community.
\end{abstract}

Co-production can lead to increased innovation and efficiency in the project design, operation and closure, not only with the affected community in mind, but also in collaboration with stakeholders. This process has shown to increase community satisfaction and introduce a greater sense of local ownership, which can be demonstrated by two practical examples discussed in this paper. While companies have an important role to play in contributing to a sustainable post-closure scenario, it is neither possible, nor their sole responsibility, to achieve it alone. It requires multi-stakeholder partnerships where risks, responsibilities and opportunities are shared. By acknowledging the contribution that communities can make in the sustainable operation and closure of mines, mining companies can use the concept of co-production to obtain greater acceptance or approval by local communities and stakeholders of their organisation and its operations, also known as their social licence to operate.

Keywords: social license, social closure, social transitioning, resilience, legacy, co-production

\section{Introduction}

For decades, the Republic of South Africa has been one of the world's leading mining and mineral-processing countries (Yager 2004). While mining has helped to shape South Africa more than any other industry, its substantial impact on the biophysical and social environment has not gone unnoticed. Ranging from its polluted environments, to acid mine drainage and deserted mining towns, mining has unfortunately left South Africa with a significant economic, social and environmental legacy (Ackerman et al. 2018; Ntema et al. 2017; van Tonder et al. 2009).

The gold mining sector no longer dominates the South African economy as it once did. For example, gold mining companies have had only two years of positive annual growth in the last 20 years (in 2002 and 2013), with Statistics South Africa (Stats SA) showing that South Africa produced 83\% less gold in 2018 than it did in 1980 (Stats SA 2018). Further, the Department of Mineral Resources (DMR) reported that the labour force within the gold mining industry has declined from 339,000 individuals in 1997 to approximately 112,000 in 2017 (DMR 2017; Stats SA 2017). In addition, a 2009 report by the Auditor General (AG) of South Africa (AG 2009) found that 5,906 South African mines were officially listed as abandoned mines (i.e. derelict and ownerless). 
The report found that:

"...despite the significance and extent of the environmental impact of unrehabilitated abandoned mines, measures were not in place to ensure that abandoned mines were rehabilitated effectively and timeously. This resulted in the environmental and social impacts of these mines not being addressed, a lack of accountability, delays with the progress of planned projects, and inefficient service delivery." (AG 2009)

The report concluded that a general lack of policy and regulatory guidelines meant that the DMR had no recourse to enforce the rehabilitation of abandoned mines. Historically, the DMR, through the implementation of the Mineral and Petroleum Resources Development Act (MPRDA; South Africa 2002) was mandated to regulate mining activities. This changed in 2014, when the National Environmental Management Act (South Africa 1998) (NEMAL was amended to delegate oversight in terms of the environmental aspects of mining to the Department of Environmental Affairs (DEA) whilst the DMR remained the permitting authority. Amendments to NEMA in 2015 and again in 2017 for the first time included aspects relating to mine closure and rehabilitation with the promulgation of the Regulations Pertaining to the Financial Provision for Prospecting, Exploration, Mining or Production Operations (Regulation 1147, 20 November 2015). It is acknowledged that these additions to the South African legislation are a positive change to ensure that the mining industry commits to responsible environmental management and to the concept of sustainable development during operations and closure. However, the regulations predominantly focus on rehabilitation and remediation of biophysical impacts and not on the social impacts related to closure despite the substantial associated impacts and potential risks.

In the absence of clear guidelines for social transitioning to mine closure, the MPRDA makes provision for a Social and Labour Plan (SLP) which, at its core, aims to ensure that mines contribute towards the socioeconomic development of the areas in which they are operating. Although the SLP does not explicitly address the impacts of mine closure nor the impacts associated with transitioning to closure, some of the provisions aim to ensure that procedures are in place to support the process. Regulation 46 (d) of the MPRDA, for example, requires mines to put measures in place to manage downscaling and retrenchment. One of the first requirements of Regulation 46 is to establish a so-called future forum which must serve as a mechanism where mine management engages with employees, government authorities, communities and civil society organisations. The objective of this forum is to anticipate downscaling or closure and manage potential retrenchments on a basis that is informed by the skills development process which also forms part of the SLP. The DMR (DMR n.d.) provides additional guidelines in terms of the roles and responsibilities of this forum which focuses on promoting the continuous monitoring of productivity and developing turnaround and redeployment strategies to improve business sustainability where needed.

Further mechanisms that are required by Regulation 46 (d) of the MPRDA include measures to save jobs and avoid job losses and a decline in employment. Where job losses cannot be avoided alternative solutions and procedures should be provided for creating job security. The goal is to mitigate the social and economic impact on individuals, regions and economies where retrenchment or closure of the mine is certain. If the profitability and downscaling of mining operations affect employment, the MPRDA requires a mine to consult with trade unions or other relevant parties, notifying them of potential cut-backs and report on the socio-economic and labour implications thereof. Where downscaling and retrenchment cannot be avoided, mines are required to provide a plan in terms of Section 189 of the South African Labour Relations Act (Act 66 of 1995).

With approximately 6,000 abandoned mines and many more, under care and maintenance or facing closure soon, South African legislation does not provide sufficient guidance on mine closure, specifically from a social perspective. According to Lake (in Moolman 2016) South African has been lagging behind the rest of the world in terms of the implementation of mine closure and the establishment of rehabilitation regulations. Lake (in Moolman 2016) notes that: "the softer issues like rehabilitation, mine closure and community development have not received the attention they deserve. It is not that we have been doing nothing, we haven't been doing enough". There is a requirement for additional guidelines to be developed through practical experience to address the requirements for mine closure, especially from a social transitioning point of view. 
Following on from the financial provision regulations promulgated in 2017, amended regulations have recently been released for public comment (Government Notice 667, 17 May 2019). The regulations, however, still do not provide guidance on addressing the financial implications linked to adequate social closure. Once legislation is promulgated into South African law, guidelines are normally developed to assist affected parties to comply with the legislation. The development of guidelines for financial provisioning for closure will aid in addressing the requirements for mine closure, especially from a social transitioning point of view. This will, however, require an extensive effort from mining companies as well as various environmental and social assessment practitioners and non-governmental organisations to motivate such guidelines to the DEA and DMR. At present, some mining companies are voluntarily compiling their own guidelines for provisioning for social closure as a best-practice initiative.

Within this setting, the authors acknowledge that there is a lack in guidance frameworks and tools to effectively plan for social transitioning. This paper therefore explores methodologies that can aid the mining industry in preparing for the process of transitioning, keeping in mind the ultimate goal of building resilient communities that are equipped to adapt to a post-mining future.

\subsection{Status quo of mine closure legislation and good practice in South Africa}

The concept of mine closure is rapidly emerging as a central theme in the contemporary discourse around relationships between the mining industry and mining-affected communities. This is especially true within the South African context, where the mining industry is now contributing less to the global mining industry, with many mines downscaling or closing.

At the end of its life, a mining operation in South Africa is required by legislation to undertake certain closure activities to achieve a post-closure landscape where the environmental and social risks are acceptable, both to the mine as well as to the stakeholders directly and indirectly affected. According to the MPRDA, the owner of a mine remains responsible for all liabilities related to that mine until a closure certificate has been issued. Sections 41 and 43 of the MPRDA further require the owner to make financial provision for all environmental liabilities related to the mine.

The financial provision regulations were promulgated under the NEMA and brought about major changes in the way in which costs for closure are calculated. The NEMA rehabilitation requirements are principles-based and therefore not prescriptive as the MPRDA requirements were prior to its introduction. Apart from immediate and final rehabilitation provisions in cash, guarantees or trusts, mining companies now have to make a separate provision specifically in a trust fund for latent and residual effects of mining for at least 10 years after the mine closes.

Under the new regulations, mining companies must undertake three basic risk assessments for closure planning every year: one for immediate closure, one for final closure and one for residual and latent effects, which must be carried out by an independent specialist and signed off by an external financial auditor. The objective of the risk assessments is to understand the financial obligation which the mining company will be liable for, depending on the closure situation. These risk assessments mainly focus on the environmental liability of closure and do not consider the social aspects of closure. Even though these activities may add to operational costs, it allows companies to properly budget for transitioning to either immediate or planned closure and for any residual or latent event post-closure.

Even though the regulations hold the owner of the mining rights legally accountable for the latent environmental liabilities at their operation in accordance with MPRDA and NEMA, there is still very little guidance provided in terms of the establishment of mechanisms for social transitioning to and beyond mine closure. South African legislation in the form of the NEMA and MPRDA regulations have given thought to the social implications of mine closure, including the requirement to develop a SLP, however, some measures that are required by the SLP counteract social transitioning objectives. One such example is the requirement for mines to address the housing and living conditions of the mine employees during operations, without giving thought to the post-closure consequences that may arise. Lawrie et al. (2011), for example, argue that generating housing assets in mining communities seldom takes into consideration the long-term implications 
of the social disruption generally associated with downscaling or closure and it could lock households into locations that are not economically viable. The Minerals Council South Africa (n.d.) further highlights that establishing "mining towns" is often not sustainable, as "migrant employees do not wish to move to mining towns on a permanent basis, preferring to maintain and return to their homes in rural areas". The establishment of permanent mining towns has been shown to inhibit mobility and has the potential to entrench households in poverty (Ntema et al. 2017).

The socio-economic development aims of the MPRDA are also clear in its requirement for mines to provide plans on increasing the procurement of local and historically disadvantaged companies. However, measures to consider the sustainability of these interventions post-closure are not addressed. Very few suppliers are able to remain economically viable after mine closure. Other requirements, such as the need for local economic development projects as part of the SLP, tend to focus more on infrastructure development rather than generating lasting post-closure economic opportunities for the mining-affected community.

\subsection{The social and environmental implications of mine closure}

Lake, in Oosthuizen (2019), notes that the technical, financial, social and environmental implications of closure are largely dependent on when and how mine closure occurs. Unplanned closure can, for example, result in a workforce facing imminent retrenchment and loss of livelihood; at the same time, communities may potentially lose the support provided by a mine, and suppliers' contracts are cancelled. Where an unexpected decline in mining activity takes place, mining communities have experienced a sudden depopulation (Petrov 2010), declining standards of living among mineworkers (Haney \& Shkaratan 2003), community instability (Jackson 2002), and long-term health problems among miners and in mining communities (Holton et al. 2002). Ntema et al. (2017) further point out that unplanned mine closure, coupled with the undiversified skills sets of mine workers, often results in a delayed economic diversification of communities.

The stage of a mine's closure planning process will therefore affect not just the implications that the mine faces with regard to its biophysical environment, for example in terms of the rehabilitation process and associated costs, but also its socio-economic environment and other reputational aspects. Burns \& Church (2018) note that these social impacts of closure can be real or perceived and the changes brought by closure can be both positive and negative. These impacts commonly include changes to the community's economic structure such as employment and business opportunities, as well as community dynamics such as changes in demographics (Burns \& Church 2018). Other implications of mine closure relate to the local government's capacity or ability to take over the responsibility of services including local emergency, education or health services. This is either because these services have previously been provided by the mining company, or due to a reduction in government revenues (Burns \& Church 2018).

Furthermore, unmanaged environmental impacts resulting from mining operations can be prolonged and negatively affect future land access and use. A case in point is the rising groundwater levels in the Witwatersrand of South Africa due to the pre-mature closure of mines (McCarthy 2011). Rising groundwater levels have the potential to impact on the quality of water supplies and crops in these areas, which could result in negative impacts on both human health and the health of wildlife and eco-systems in the surrounding environments.

Lake, in Oosthuizen (2019), state that a mine's transitioning towards closure should ideally include adequate budget to implement remedial measures and allow as much time as needed for the affected labour force to seek alternative employment or livelihood replacements. It is therefore of paramount importance that closure plans for mines not only include a realistic and updated provision for biophysical closure but that they consider the cost and planning for social closure as well. Lake, in SA Mining (2017) concludes that "carefully managing the social impact issues allow a mine to hold on to the reputational capital it has built up over years of engagement with its communities and employees". 


\subsection{The importance of a mine closure plan to address social matters}

Closure plans are not only a legal requirement in terms of the South African legislation, but as other commentators have indicated, they are "an important aspect of a mine's social licence to operate and therefore, mines should not approach their closure responsibilities as a purely compliance exercise" (Malebana, pers. comm, 22 March 2019). To reach a sustainable outcome, a long-term approach is required in which the mine operation builds stakeholder relationships, institutional memory and cumulative knowledge about which strategies work and which do not (Oosthuizen 2019).

Even with the absence of clear guidelines on mine closure, the mining industry has over the last 15 to 20 years started to recognise the benefits of planning for closure as early on in a mine's lifecycle as possible. The environmental gains made in this respect, have unfortunately not been matched by the level of awareness on social aspects of mine closure. According to Owen \& Kemp (2017), the mining industry has failed in embedding 'social performance capabilities' that are required to consistently identify key social risks and trends, undertake analysis and manage operations in complex socio-political environments and minimise social impacts. Since social aspects certainly do not form part of the core business of most operations, mine management can shy away from actively addressing social closure planning presumably due to a fear of the unknown and unexpected. Other likely reasons for this includes the lack of in-house capabilities to understand the complex effects of closure on mining-affected communities. This avoidance can also be attributed to the ineffectiveness of organs of state tasked with the enforcement of the closure requirements (Liefferink 2009:6; Olalde 2016).

The focus of social closure planning is often placed on how to deal with the physical infrastructure such as mine offices or the cost of retrenchment packages. Questions of human sustainability, such as alternative livelihoods for affected communities are more difficult to address and often the mine may not have experience or expertise in these fields. According to Lake (Oosthuizen 2019), mining consulting companies generally advise that mines avoid viewing closure planning as a linear process, and rather address closure planning early in the mine lifecycle. Plans for transitioning to closure should therefore be developed in an iterative manner as more information on the mine's performance, impact and potential closure risk becomes available.

During this lifecycle, stakeholder requirements and expectations change, however, with proper planning these requirements can aid in enhancing the closure outcomes of a mine. This can be challenging during the earlier phases of the project lifecycle, prior to project development, where information is sensitive, and the mining company is hesitant to create stakeholder expectations. Mining companies need to develop and formalise clear stakeholder communication protocols for each phase of the project. The communication protocol may for instance embed the level of confidentiality for each project phase, allowing for appropriate levels of disclosure throughout the lifecycle of the mine, including planning for sustainable social and environmental closure. The level of disclosure should always consider the overall objective, which is to facilitate stakeholder engagement that will establish common trust and contribute towards a lasting legacy for the mining company.

By not adopting an iterative approach, mines run the risk of not embedding the lessons learned from various trials undertaken to test closure approaches in institutional systems and practices. The life of a mine often extends beyond the careers of mine employees, reinforcing the need for these experiences to be recorded and documented. Mines that fail to address closure planning at every stage of the lifecycle may not be adequately prepared for the socio-economic risks and will face a significant number of uncertainties at the end-of-mine-life.

\section{Approaches to the management of social transitioning}

Bainton \& Holcombe (2018) support the argument that that there is little known about potential mechanisms that can be used to address the social aspects of mine closure. The socio-economic challenges and risks associated with mine closure often becomes unmanageable when pressures build due to financial constraints 
caused by a decline in production rates, unfulfilled socio-economic development expectations and increased complexity surrounding legacy issues develop (Bainton \& Holcombe 2018). According to Bainton \& Holcombe (2018), the inability of mining companies to manage these risks can contribute towards the impoverishment of the community, trigger the loss of key services and lead to out-migration. If the social transitioning of mine closure is not managed properly, Bainton \& Holcombe (2018) warn that the exacerbation of these negative consequences of mine closure can damage corporate reputations. Therefore, planning for and achieving sustainable 'social closure' is as important as the mine's responsibility to manage social impacts such as dust and noise during its operations. Over recent years, mining companies such as the Anglo American Corporation and Ivanhoe have begun to realise the importance of addressing social impacts as an important part of their legal licence agreements. According to Hart (2015), the concept of building partnerships between the mining industry, governments, regulators and society, including mining-affected communities, has rapidly emerged as a central theme to social development. Anglo American Corporation's "Social Way" (Anglo American 2014), for example, allows them to implement policies and management practices that addresses their social licence to operate, beyond their legal compliance. In reality, attention to social closure is often not a priority for mines, with many companies unsure about how to address the issue effectively. Mining companies commonly make the mistake of avoiding or postponing social strategies geared towards achieving sustainable closure. Delaying the planning for social transitioning may be costly for mining companies, both financially and in terms of reputational damage after closure. This would mean that the mine does not leave a lasting legacy that includes sustainable post-mining opportunities for mining-affected communities.

Mining companies need to consider practical local economic opportunities for the mining-affected community's future and collaborate with local partners and communities towards a sustainable future beyond the life of the mine. Within the South African context, legislation in the form of the MPRDA and its requirement for a future forum has already envisioned the benefits of co-production. Co-production, either through this platform or similar bodies where stakeholders are capacitated to aid the mine in its social transitioning objectives can assist in sensitising mining-affected communities to the eventual closure of the mine and build their resilience to transition through the closure process.

In the absence of tools and methodologies to assess and mitigate for social closure, the following sections present potential alternative approaches that mining companies can utilise to manage their social transitioning process. The authors present two examples, one in a local government- and the other in a mining context, where the concept of co-production was applied. Finally, an example is presented of where planning for community resilience has worked successfully to achieve sustainable post-closure communities.

\subsection{Using the concept of co-production in social transitioning}

The concept of co-production has been defined as (Parks et.al 1981): "a process through which inputs used to produce a good or service are contributed by individuals who are not 'in' the same organisation." The concept was further developed in the public services delivery arena where communities were involved in developing economic development programmes (Alford 1998; Carr 2016; Needham 2008).

The benefits of this approach, arising from research in this area include:

- A collaborative approach is followed by deviating away from the top-down decision-making method of imposing ideas on communities.

- The creation of supportive social networks (Boyle \& Harris 2009).

- Inclusion of not just local stakeholders such as local government departments, but also communities in project planning and design (Alford 1998).

- Increased consultation with stakeholders, in addition to ensuring that a range of stakeholders participate in the conception, design, steering and management of projects (Alford 1998). 
- Increased innovation and efficiency when projects are designed with the affected community and other stakeholders in mind (Alford 1998).

- Increased community satisfaction and a greater sense of local ownership, leading to more cohesive, resilient communities (Alford 1998).

The author indicates that co-production is gaining broader recognition, especially in municipal service delivery and infrastructure development projects. Case studies presented in the paper illustrate how the process of 'co-production' produces many benefits as an approach to social closure.

At the core of the co-production approach is building strong relationships between stakeholders, including co-funders, development partners or government organisations, based on a common vision for the community's future beyond the life-of-mine. Such collaboration also helps build social resilience and forge alternative livelihood strategies to transition into a sustainable post-mining phase as the examples will show.

The examples presented in this paper further show that increased community involvement usually leads to higher levels of 'buy-in' to project proposals as stakeholders get to assess the project in more detail and weigh up benefits and trade-offs. Co-production also allows the community to participate in developing a vision for the future, including a future that is not solely dependent on mining. Such a vision has a practical value, creating the foundation for stakeholders from different backgrounds to collaborate towards a common goal. Routine collaboration is vital for establishing a sense of partnership and cooperation, so inevitable challenges can be constructively addressed, and proactive mitigation measures put in place. This continuous capacity development encourages local partners to take ultimate responsibility for the future social and economic development of the community beyond the mining company's own involvement.

By acknowledging and further developing the roles that local partners play in the operation and closure of mines, mining companies can use the concept of co-production to earn a social licence to operate. They can also use the collaboration process to build confidence and capacity in local partners and encourage them to take ownership of their own social and economic wellbeing. The examples below show how co-production reduces the dependency of communities on a single employment source such as mining and builds the resilience of the community and other support structures to transition through the mine's closure and the related social consequences.

The key, however, is for mining companies to apply the co-production approach well in advance of the actual closure phase of a mining operation, preferably from the start-up stage. Even though it commonly takes 1020 years to build sustainable, alternative livelihoods to mining, the examples presented below show that, by making social development independent of the life-of-mine, co-production can also be implemented at any stage of mine closure.

\subsubsection{Co-production in a local government context}

Between 2016 and 2019 the Johannesburg Development Agency (JDA) embarked on a process to revitalise the Noordgesig community situated within Soweto, South Africa. During the infrastructure development process, the community's input had been essential to arriving at a vision for Noordgesig. As part of the community engagement, the JDA (2016) presented and sought community comment on a number of potential projects and explained that the consultation process was "built on the realisation that the production and consumption of many services are inseparable. The quality and strength of a service and an effective design depends upon close interaction, if the community does not contribute fully and creatively to the process, it is likely to be less effective in its outcomes."

According to the JDA (2016), this new approach enhanced community ownership by encouraging a collaborative approach between local authorities, professional service providers and the community. This was supported by community feedback. In a documentary video prepared by JDA a community member summarises the process (JDA 2017) as follows: "I think when people participate in the development of Noordgesig, I think they will look after things and I think they will part of it. If people don't participate they will feel like the authorities just came and put down things they didn't want". In the same documentary video 
(JDA 2016) another community member highlights the benefits of the inclusive approach: "They will own the whole project and they will take care of it". The JDA (2016) adds that: "The importance of co-producing design leads to ownership...the project that we deliver is sustainable...it has a longer life span and a much better success rate".

The project in Noordgesig is a good example of co-production as it did not only rely on the input of community members to determine which infrastructure development they needed. The community was also instrumental in the construction of the product ultimately designed. As part of the JDA's development objectives, a portion of the construction contract value was awarded to small and medium construction companies within the community. Throughout the construction process, opportunities for training and skills development were provided not only to the emerging construction companies, but also to labourers sourced from within the community.

The benefits of co-production in this context included a much more sustainable sense of ownership, civic pride and citizenship.

\subsubsection{Co-production in the mining context}

In 2009, Anglo American Platinum (AAP) used the vehicle of equity ownership in the form of the Alchemy project to bring benefits directly to host and neighbouring communities (Hart 2015). The differentiating factor, however, according to Hart (2015), was to make long-term development resources available to mining-affected communities and to enable the communities to participate in development planning and mobilisation. The key elements that has made the Alchemy programme a good example of co-production includes the fact that the development vehicle allowed the community to hold shares and receive dividends from AAP and not from relatively short-lived individual mines (Hart 2015). According to Hart (2015), this was facilitated through a specially designed trust called the Lefa la Rona Trust which allowed mining-affected communities to plan and implement development initiatives and also be represented at board level. The establishment of the Lefa la Rona Trust allowed poor and rural mine host communities to become the third largest shareholders of APP (Leadership Magazine 2017).

The process of developing the Alchemy programme, a framework for co-production, required careful planning and engagement over a number of years. According to Hart (2015), a structured and step-wise process to grow and empower the trust was developed to promote full community ownership and to develop a culture of socio-economic sustainability. Over and above this, special care was taken to ensure that the trust was co-designed with locally-based working groups to ensure the appropriate contextual fit (Hart 2015). The area where the Alchemy programme truly allowed for co-production was the way in which it leveraged development resources in partnership with other development actors. According to Hart (2015), the trust allowed for a legitimate platform where mining-affected communities could interact equitably with potential development partners.

The Alchemy programme has shown that a long-term planning view resonates with community leadership, often weary about the post-mining outlook of their communities (Hart 2015). It further showed how coproduction has long-term benefits for communities, especially when considering mine closure planning. By co-producing the planning framework for development, AAP and the mining-affected communities were able to facilitate a partnership between the trust, the various role players in government as well as the private sector which led to sustainable development opportunities.

\subsection{Developing resilient mining-affected communities towards social transitioning}

Another approach to effective social transitioning after mine closure is the process of building communities' resilience in preparation for closure. Adger (2000) defines social resilience as the ability of groups or communities to cope with external stresses and disturbances as a result of social, political and environmental change. Social resilience for mining-affected communities can therefore be defined as their ability to cope with changes or stress brought about by mine closure without losing their critical functions as a community concerning social relations, economic prosperity and political stability (Abesamis et al. 2006). 
A conceptual framework for this approach is based on the four principles of resilience listed by Folke et al. (2003) which include:

- The level of adaptability within the community.

- The ability to reorganise and renew.

- The community's ability to combine different types of knowledge for learning.

- Its ability to self-organise.

In order to assess the level of resilience within a community, focused engagement with key structures in the community should inform the level of alignment with these principles. Mining companies should start by establish a baseline of the community resilience by investigating and assessing the established livelihoods of a community prior to the mining development taking place. Factors which have improved or discouraged livelihood strategies should be noted and analysed.

For existing mining operations, the process of measuring resilience can include the analysis of indicators such as the number of household members that are employed by the mine, or the percentage of local companies that provide goods or services to the mine. Mining companies could engage their suppliers to determine, in a confidential manner, their reliance on the operation.

There are several steps a mine can take to determine a community's reliance on their operation. These steps could include:

- Ttaking an inventory of all the commitments the mine has made, for example in terms of land lease agreements, investments into community infrastructure such as schools, community halls and health facilities.

- Identifying areas where specific weaknesses in resilience could occur, for example, where the mining-affected community is solely reliant on the mining company for water treatment facilities.

- Investigate the best and most suitable options for addressing the weakness.

- In consultation with the community develop and implement mitigation measures, the gradual handover of infrastructure, knowledge or skills to the local authority or other capable community platform.

Another approach to determining a community's resilience is to identify the community needs, their current livelihood strategies and any opportunities for diversifying these livelihood strategies. This would assist in fortifying communities against mine closure, as is shown in the Ivanhoe Kamoa-Kakula mine example provided below.

The process of determining a community's resilience should ideally start by determining the current level of dependence of employees and families on the existing operation. This understanding can be developed through an actor or decision maker mapping exercise, which allows you to understand the network of actors within a specific context (Morelli 2009). This mapping exercise helps to understand the direct and indirect relationships between the different role players within a mining-affected community. According to Malebana (in Leadership Magazine 2019), stakeholder mapping also allows the user to understand the community power- and decision-making dynamics, which will further inform the resilience of a community.

Stakeholder mapping and engagement with secondary service providers to the mine (i.e. educational institutions, rental housing providers and local supermarkets) as well as local leadership structures (i.e. local authorities) and civil society groups also builds an understanding of the synergies needed to create resilient communities.

Through the development of a clear understanding of the mine stakeholders and the way in which they interact with each other, mining companies can start developing a framework to assess the community's resilience to the impacts of mine closure. Such a framework should firstly assess the level of agency a community has as well as the level to which they can self-organise. Flowing from this, the framework should 
seek to assess the community characteristics, as described by Berkes \& Ross (2013). Characteristics include: people-place connections; values and beliefs; knowledge, skills and learning; social networks; engaged governance (involving collaborative institutions); a diverse and innovative people-place connections economy; community infrastructure; leadership; and a positive outlook, including readiness to accept change. The way in which these characteristics combine to produce the process of resilience should be the ultimate goal of the framework. A community's ability to influence resilience and an individual or group's capacity to act independently are both highly important to this process (Berkes \& Ross 2013).

\subsubsection{Building resilience at Ivanhoe's Kamoa-Kakula mine and affected communities}

Ivanhoe Mines runs a number of operations in South Africa and Democratic Republic of Congo (DRC). At its Kamoa-Kakula mine in southern DRC a sustainable livelihoods project was established around 14 communities in the areas surrounding the Kamoa-Kakula mine. The project, which was initiated in 2012, aims to support eco-livelihoods and contribute to the economic empowerment of the mining-affected people. Subsistence agriculture is the primary livelihood base and source of income for the majority of households in the project area, and a large proportion of the population are dependent on natural resources for drinking water.

A social and environmental screening study, which was undertaken in 2008 , determined that the high level of poverty has led to food insecurity within the development area. During 2010, Ivanhoe commissioned a study tour in association with the community leadership to determine community needs and workshop sustainable development programmes to address the impacts of poverty and food insecurity. During the consultation process, the parties concluded that an agricultural programme would best mitigate the impacts associated with food security and aid in raising the overall wellbeing of the community members. The programme was designed in such a way that allowed Ivanhoe to hand over the programme initiatives to the community leadership, whilst still monitoring the implementation progress. As a testament to their success, Ivanhoe has already handed over a number of these initiatives to the surrounding communities who are currently operating these without any assistance from the mine.

These projects are not only contributing towards the establishment of sustainable livelihoods, but resourceefficient agriculture is contributing to environmental conservation, enhanced and sustained agricultural production and ensuring that benefits reach the widest possible spectrum of the community. In addition, forested areas previously degraded by unsustainable clearing are being rehabilitated with tree-planting activities and managed harvesting. Farmers in the area are being trained in market-gardening and irrigation techniques for year-round food production and solar-powered dryers are being used to prepare fruits and vegetables for storage.

Even though Ivanhoe is only in the early development phase of their Kamoa-Kakula mining operation, it has shown how early engagement can lead to positive impacts for the mining operation and the community. By establishing a sustainable community livelihood initiative with opportunities for further development through the life of the operation, Ivanhoe has proactively assisted the mining-affected community to build their resilience against the eventual closure of the mine.

\section{Conclusion}

The once dominant South African mining industry is increasingly faced with the realities of mine closure, and with the absence of clear guidance on how to facilitate this closure, the social aspects of mine closure are often the elephant in the (board)room.

Much progress has been made to increase the awareness around a mining company's social license to operate, however, very little progress has been made in terms of understanding how the neglect of social closure obligations can also lead to reputational damage.

In acknowledging that insufficient guidelines towards social closure are available the authors have attempted to highlight the importance of drawing on established community development approaches towards 
sustainable mine closure. The concept of co-production can be used as one such approach and evidence of its success in a local government context as well as a mining context was provided. It was shown how the process of co-production can lead to increased innovation in terms of establishing sustainable livelihood strategies that doesn't solely rely on mining.

Another approach to ensuring sustainable mine closure through the assessment of a community's resilience was presented. By implementing the basic principles of this approach into the early assessment of a community livelihood strategies, effective measures were put in place to strengthen their autonomy as well as their capacity to adapt to change.

These approaches have on different occasions shown how mining companies, in collaboration with stakeholders can build on proven community development approaches to build resilient and cohesive communities that are equipped to transition through the negative effects of mine closure. Where opportunities present themselves, communities could add considerable value and insight into the sustainable operation- and the ultimate closure of mines. To maximise this benefit, mining companies can use the concepts presented in this paper to obtain, not only a social licence to operate but also a sustainable postmining future for mining-affected communities.

\section{Acknowledgement}

The authors acknowledge and thank James Lake, Adel Malebana, Darryll Killian and Tim Hart from SRK Consulting (South Africa) (Pty) Ltd, South Africa for their contributions and guidance. The authors also acknowledge the excellent work undertaken by Anglo American Platinum, Ivanhoe and the JDA and recognise the additional input provided by Lisl Fair, Group Manager for Social and Investment at Ivanhoe Mines SA (Pty) Ltd.

\section{References}

Abesamis, NP, Corrigan, C, Drew, M, Campbell, S \& Samonte, G 2006, Social Resilience: A Literature Review on Nuilding Resilience into Human Marine Communities in and Around MPA Networks, MPA Networks Learning Partnership, Global Conservation Program, USAID, Washington DC.

Ackermann, A, Botha, D \& van der Waldt, G 2018, 'Potential socio-economic consequences of mine closure', The Journal for Transdisciplinary Research in Southern Africa, vol. 14, no. 1, https://doi.org/10.4102/td. v14i1.458

Adger, WN 2000, 'Social and Ecological Resilience: Are They Related?', Progress in Human Geography, vol. 24, pp. 347-364.

Alford, J 1998, 'A public management road less travelled: clients as co-producers of public services', Australian Journal of Public Administration, vol. 57, no. 4, pp 128-137.

Anglo American 2014, Social Way, London.

Auditor General 2009, Report of the Auditor-General to Parliament on a Performance Audit of the Rehabilitation of Abandoned Mines at the Department of Minerals and Energy, viewed 12 March 2019, https://cer.org.za/wp-content/uploads/ 2011/10/AG_Report_on_abandoned_mines-Oct-2009.pdf

Bainton, N \& Holcombe, S 2018, 'A critical review of the social aspects of mine closure', Resources Policy, vol. 59, pp. 468-478.

Berkes, F \& Ross, H 2013, 'Community resilience: toward an integrated approach', Society \& Natural Resources, vol. 26, no. 1, pp. 5-20, https://doi.org/10.1080/08941920.2012.736605

Boyle, D \& Harris, M 2009, 'The challenge of co-production', London: New Economics Foundation, pp. 185-194.

Burns, C \& Church, J 2018 'Managing the social impacts of mine closure', Canadian Mining Journal, viewed 27 May 2019 , http://www.canadianminingjournal.com/features/managing-the-social-impacts-of-mine-closure/

Carr, S 2016, 'Can co-production really transform UK mental health services?', blog post, Mad in America: Science, Psychiatry and Social Justice, viewed 20 October 2016, https://www.madinamerica.com/2016/08/can-co-production-really-transform-ukmental-health-services/

Department of Mineral Resources 2017, Public Labour, viewed 12 March 2019, http://www.dmr.gov.za/Portals/0/files/ Public\%20Labour\%202017Q3.xls?ver=2018-03-09-110312-557

Department of Mineral Resources n.d., Social and Labour Plan Guidelines, viewed 12 March 2019, http://www.dmr.gov.za/Portals/0/social\%20and\%20labour\%20plan_guideline.pdf

Folke, C, Colding, J \& F Berkes 2003, 'Synthesis: building resilience and adaptive capacity in social-ecological systems', in F Berkes, J Colding \& C Folke (eds), Navigating Social-ecological Systems: Building Resilience for Complexity and Change, Cambridge University Press, Cambridge, pp. 352-387.

Haney, M \& Shkaratan, M 2003, Mine Closure and its Impact on the Community: Five Years after Mine Closure in Romania, Russia and Ukraine, World Bank, Washington DC. 
Hart, T 2015, 'Mines and sustainable communities: seeking platforms for true development partnership', Proceedings of the Third International Conference on Social Responsibility in Mining, Gecamin, Santiago.

Holton, D, Kelly, M \& Baker, A 2002, 'Paradise lost? Assessment of liabilities at a uranium mine in the Slovak Republic: Novoveska Huta', Geological Society Special Publication, vol. 198, pp. 355-377.

Jackson, R 2002, Capacity Building in Papua New Guinea for Community Maintenance During and After Mine Closure, International Institute for Environment and Development, London.

Johannesburg Development Agency 2016, New Era Beckons for Noordgesig as Development Plan is Approved, Johannesburg, viewed on 27 May 2019, https://www.jda.org.za/new-era-beckons-for-noordgesig-as-development-plan-is-approved/

Johannesburg Development Agency 2017, Noordgesig Precinct Project, video file, https://www.youtube.com/watch?v=vjZNHF87o-8

Lawrie, M, Tonts, M \& Plummer, P 2011, 'Boomtowns, resource dependence and socio-economic well-being', Australian Geographer, vol. 42, no 2, pp. 139-164.

Liefferink, M 2009, Submissions to the Karoo Development Conference and Trade Fair Proposed Uranium Mining Within the Beaufort West Area, The Federation for a Sustainable Environment, Bryanston, viewed 26 September 2017, http://www.fse.org.za/ Downloads/URANIUM\%20MINING\%20KAROO.pdf

Leadership Magazine 2019, 'Map your stakeholders to fully understand expectations and risk', Leadership Magazine, Cape Town, viewed 27 May 2019, http://www.leadershiponline.co.za/articles/map-your-stakeholders-to-fully-understand-expectationsand-risk-28305.html

Leadership Magazine 2017 'Facing her biggest challenge yet-food security', Leadership Magazine, Cape Town, viewed 27 May 2019 , http://www.leadershiponline.co.za/articles/facing-her-biggest-challenge-yet-food-security-23802.html

McCarthy TS 2011, 'The impact of acid mine drainage in South Africa', South African Journal of Science, vol. 107, no. 5/6, viewed 23 May 2019, https://doi.org/10.4102/sajs.v107i5/6.712

Minerals Council South Africa n.d., Housing and Accommodation in the South African Mining Industry, Johannesburg, viewed 26 March 2019, https://www.mineralscouncil.org.za/industry-news/publications/fact-sheets/send/3-fact-sheets/739housing-and-accommodation

Moolman, V 2016, 'South Africa behind global curve', Creamer Media's Mining Weekly, viewed 27 May 2019 , https://www.miningweekly.com/article/s-africa-behind-global-curve-2016-11-11

Morelli, N 2009, 'Service as value co-production: reframing the service design process', Journal of Manufacturing Technology Management, vol. 20, no. 5, pp. 568-590.

Needham, C 2008, 'Realising the potential of co-production: negotiating improvements in public services', Social Policy and Society, https://doi.org/10.1017/S1474746407004174

Ntema, J, Marais, L, Cloete, J \& Lenka, M 2017, 'Social disruption, mine closure and housing policy: evidence from the Free State Goldfields, South Africa', Natural Resources Forum, vol. 41, pp. 30-41.

Olalde, M 2016, 'SA's failed system of mine closure', IOL, viewed 26 September 2017, from https://www.iol.co.za/news/opinion/sasfailed-system-of-mine-closure-7117963

Oosthuizen, J 2019, 'Demand likely to grow for mine-closure expertise', Mining Weekly, viewed 26 April 2019, https://www.miningweekly.com/article/demand-likely-to-grow-for-mine-closure-expertise-2019-04-26/rep_id:3650

Owen, J, \& Kemp, D 2017, Extractive Relations: Countervailing Power and the Global Mining Industry, Routledge, London.

Parks, RB, Baker, PC, Kiser, L, Oakerson, R, Ostrom, E, Ostrom, V, Percy, SL, Vandivort, MB, Whitaker, GP \& Wilson, R 1981, 'Consumers as coproducers of public services: Some economic and institutional considerations', Policy Studies Journal, vol. 9, no. 7, pp. 1001-1011.

Petrov, A 2010, 'Post-staple bust: modeling economic effects of mine closures and post-mine demographic shifts in an arctic economy (Yukon)', Polar Geography, vol. 33, no. 1-2, pp. 39-61.

SA Mining 2017, 'A mine's fastest way out of the (re)starting blocks', viewed 12 March 2019 , https://www.srk.co.za/sites/default/files/File/South-Africa/pressreleases/2017/May_2017/SA_Mining_A_mines_fastest_ way_out_of_the_restarting_blocks_01May17_p.20-p.22.pdf

South Africa 1998, National Environmental Management Act, No. 107 of 1998.

South Africa 2002, Mineral and Petroleum Resources Development Act, No. 28 of 2002.

Statistics South Africa 2018, Mining Production Stumbles in 2018, Salvokop, viewed 12 March 2019, http://www.statssa.gov.za $/ ? p=11921$

Statistics South Africa 2017, Environmental Economic Accounts Compendium, Report No.: 04-05-20, Salvokop, viewed 12 March 2019 , http://www.statssa.gov.za/publications/Report-04-05-20/Report-04-05-20March2017.pdf\#page =54

van Tonder, DM, Coetzee, H, Esterhuyse, S, Strachan, L, Wade, P \& Mudau, S 2009, 'South Africa's challenges pertaining to mine closure - development and implementation of regional mining and closure strategies', in AB Fourie \& M Tibbett (eds), Proceedings of the Fourth International Conference on Mine Closure, Australian Centre for Geomechanics, Perth, pp. 79-91.

Yager, TR 2004, 'The mineral industry of South Africa', US Geological Survey Minerals Yearbook 2004, US Geological Survey, Reston, viewed 26 April 2019, https://www.usgs.gov/centers/nmic/international-minerals-statistics-and-information 